\title{
Experimentação e prudência no pensamento rizomático de Deleuze e Guattari
}

\author{
Experimentation and prudence in the rhizomatic thought of \\ Deleuze and Guattari
}

\author{
Danilo Melo $^{\mathrm{a}}$ \\ a Universidade Federal Fluminense, Rio das Ostras, Rio de Janeiro, Brasil - danilomelo.uff@gmail.com
}

Keywords: Rhizomatic Operation. Deleuze. Guattari. Multiplicity. Ethic.

\author{
Palavras-chave: \\ Operação \\ Rizomática. \\ Deleuze. \\ Guattari. \\ Multiplicidade. \\ Ética.
}

Resumo: A perspectiva rizomática no pensamento de Deleuze e Guattari consiste numa "ruptura de escala" de análise da realidade, na qual deixamos de percebê-la como pura unidade, seja no sujeito ou no objeto. Com isso, nos fazem notar que o pensamento clássico, filosófico e científico, nunca permitiu que se compreendessem as multiplicidades rizomáticas que eles propõem, onde toda forma de unidade é excluída. A partir da operação rizomática de subtração da unidade como imagem de referência para toda multiplicidade (n-1), vemos emergir um modo de abordar as realidades a partir de três conjuntos de linhas que nos compõem, indivíduos ou grupos, e que se distribuem num plano de imanência em que se relacionam continuamente. As análises das linhas e de suas relações nos aproximam da questão da criação ou da produção da novidade e dos devires na obra de Deleuze e Guattari. A tarefa consiste em abrir os problemas práticos a fim de liberar as linhas, sejam as de uma vida, as de um indivíduo ou as de uma sociedade, mas para isso é necessário convocar experimentações nas quais é preciso proceder com prudência. Neste sentido, esta filosofia prática deve ser compreendida necessariamente como uma ética e o que pretendemos aqui é justamente pensar como se configura este modo dinâmico e imanente de avaliação dos riscos e dos fatores de criação que se apresentam constantemente nos mais diversos planos da realidade.

Abstract: The rhizomatic perspective in Deleuze and Guattari's thought consists in a "rupture of scale" of analysis of reality, in which we no longer perceive it as pure unity, either in the subject or in the object. Hereupon, they make us notice that the classical thought, philosophical and scientific, never allowed the rhizomatic multiplicities they propose to be understood, where every form of unity is excluded. From the rhizomatic operation of subtraction the unit as a reference image for all multiplicity (n-1), we observe a way to approach realities that emerges from three sets of lines that compose ourselves, individuals or groups, and that are distributed in a plane of immanence in which they relate continuously. The analyses of the lines and their relationships bring us closer to the question of the novelty's creation or production and the becoming in the work of Deleuze and Guattari. The task is to open up the practical problems in order to free the lines, whether those of a life, an individual or a society, but in this case it is necessary to convoke experimentations in which one must proceed with prudence. In this sense, this practical philosophy must necessarily be understood as an ethic, and what we intend here is precisely to think about how this dynamic and immanent way of evaluating the risks and factors of creation that constantly present themselves at the most diverse levels of reality is configured. 
A filosofia de Deleuze e Guattari se apresenta como um pensamento que pretende distinguir-se da pura abstração das filosofias que afastam o plano dos conceitos do plano dos contextos reais e das possibilidades efetivas de sua compreensão e intervenção na realidade. A perspectiva rizomática implica numa mudança de percepção na qual deixamos de perceber a realidade como pura unidade, seja em termos de objeto e sujeito, e passamos a percebê-la como uma multiplicidade de matérias intensivas, velocidades e fluxos, que compõem uma dimensão dinâmica e heterogênea. Ao propor esta "ruptura de escala" de percepção da realidade, Deleuze e Guattari fazem notar que o pensamento clássico, filosófico e científico, nunca permitiu que se compreendessem as multiplicidades rizomáticas, já que sempre necessitou de uma unidade forte como base da multiplicação (o uno como base do múltiplo), isto é, não compreendeu a multiplicidade da qual se exclui a unidade. Por outro lado, na operação rizomática de subtração da unidade como imagem de referência para toda multiplicidade (n-1), é preciso perguntar, para cada objeto ou fenômeno considerado, como e com que ele funciona, qual conexão permite que ele passe ou não intensidades, em quais multiplicidades ele participa e a partir de quais ele se transforma.

Caracterizando-se por sua "imanência absoluta" (AGAMBEN, 2000), o pensamento da multiplicidade sem unidade nos oferece uma perspectiva de análise e de ação fora de qualquer abordagem moral ou movimento negativo, porém apontando que o risco de recairmos neles permanece constantemente, já que "há o melhor e o pior no rizoma" (DELEUZE \& GUATTARI, 1980, p. 13). Assim, torna-se necessária uma postura ética para que se acompanhem seus desdobramentos e se avaliem os riscos de recair na totalização do uno ou na aniquilação dos dinamismos que animam os múltiplos planos da realidade.

Desse modo, a ética na perspectiva de Deleuze e Guattari não nega ou exclui aquilo a que eles resistem e criticam. Ao contrário, inclui em suas análises o Estado, o Fascismo, os Poderes, o Capitalismo, mostrando como estes elementos - que os "movimentos contestatórios", muitas vezes conduzidos pelo ressentimento, amaldiçoam e renegam radicalmente - derivam do mesmo plano abstrato que produz os diversos platôs dentro dos quais estes que contestam, e todos nós, estamos incluídos e por eles somos constituídos. Neste sentido, Deleuze e Guattari afirmam que precisamos estar atentos ao Estado que reproduzimos, aos Microfascismos e aos Poderes que exercemos, e aos 
movimentos através dos quais temos nosso desejo cooptado pelos fluxos de consumo do Capitalismo, por meio dos quais funcionamos antes a favor do que crítica e contrariamente a este.

$\mathrm{Na}$ esteira de Espinosa, Nietzsche e Bergson, o pensamento rizomático de Deleuze e Guattari é atravessado em sua singularidade por uma filosofia prática, por uma filosofia do devir e por uma filosofia das multiplicidades. Daí suas análises serem imanentes, isto é, possuírem como critério de suas avaliações a criação e o devir, e operarem um modo de abordar as realidades a partir de suas múltiplas linearidades constituintes: "[...] em qualquer coisa, há linhas de articulação ou segmentaridade, estratos, territorialidades, mas também linhas de fuga, movimentos de desterritorialização e desestratificação" (DELEUZE \& GUATTARI, 1980, p. 9-10). Não há contradição ou oposição negativa entre as linhas que compõem o real, mas combate perpétuo das forças ou dos planos que as caracterizam em suas diferentes valências. Não há ponto de partida ou início dos lineamentos, como a ponta de um novelo emaranhado ou "complicado" que se poderia tomar como a realidade original, e muito menos realidade ideal contida nestas tramas que uma vez "descomplicadas" produziriam um bordado já suposto do real, mas antes um trançar-se contínuo que só pode ser apreendido e nele enveredar pelo meio, no instante mesmo em que ele está em vias de se cruzar. Este cruzamento dinâmico dos lineamentos apresenta, por sua vez, um jogo simultâneo de resistências: resistência do real já constituído às forças de transformação, e resistência das linhas de criação à captura das forças conservadoras, ambas ao mesmo tempo. Neste jogo de forças, importa a Deleuze e Guattari resistir ao que, em uma situação concreta, deixa pouco lugar para a novidade.

O horizonte de avaliação que Deleuze e Guattari buscam depreender destas análises são as condições de mutação que podem ser apreendidas sob os modos de existência concretos e os campos sociais dados. Isto é, como uma novidade pode advir aos modos de vida e à realidade social, a partir de quais condições, por meio de que práticas, através de quais critérios? Para isso é preciso captar os devires que atravessam os indivíduos e os grupos sociais, apreender as possibilidades de mutação que eles trazem e as potencialidades criadoras que eles comportam. No entanto, não se trata de propor algum ponto de vista que viria substituir o modo de representação ordinário, mas, antes, pensar a elaboração de um conjunto de práticas que permitam relançar a experimentação, isto é, os processos 
de criação ou de fuga que resistam aos imperativos dos hábitos e dos costumes e que trabalham a favor da emergência do novo.

Neste sentido, seguindo a operação inaugurada por Bergson, Deleuze e Guattari vão desenvolver suas análises a partir de um vasto conjunto de conceitos que formam um sistema de remissão contínuo entre planos ou polos, através do qual uma dinâmica criadora se efetua ${ }^{1}$. Entre estes polos se desenrola todo um domínio de negociação ou tradução no qual se efetuam linhas moleculares, ora se inserindo em linhas molares através de fendas e fissuras, ora fazendo consistir as conexões de fluxos das linhas de fuga, tudo ao mesmo tempo. Nestes processos em que se cruzam as linhas, os fatores de criação variam constantemente e são ameaçados por riscos que portam os movimentos de cada um destes lineamentos. Para Deleuze e Guattari, cabe então avaliar os riscos que interferem nas condições de mutação e de emergência da novidade para as situações consideradas em cada caso a partir da dinâmica imanente de seus lineamentos.

Vejamos como estas linhas se caracterizam e o modo de análise dinâmico que lhes é exigido.

\section{As três dimensões do real e o método cartográfico}

De acordo com Deleuze e Guattari, somos compostos, indivíduos ou grupos, por três espécies ou conjuntos de linhas em relação contínua distribuídas num plano de imanência: linha molar, linha de fluxos moleculares e linha de fuga. Cada uma delas possui movimentos que expressam ritmos diferentes e não têm a mesma natureza.

A linha molar ou de segmentaridade dura, também chamada por Deleuze e Guattari (1980) de linha de corte ou recorte, se caracteriza exatamente por exercer um controle sobre a continuidade do tempo (duração) e daquilo que circula no campo das singularidades, produzindo uma descontinuidade espacial da temporalidade e da própria experiência afetiva em nossa sensibilidade. Ela supõe, portanto, um plano ou uma linha

\footnotetext{
${ }^{1}$ Sobre o problema da criação a partir da teoria das multiplicidades na obra de Gilles Deleuze cf. MENGUE, Philippe. Gilles Deleuze ou le système du multiple. Paris: Édition Kimé, 1994, onde o autor aborda este modelo da remissão entre os planos múltiplos que compõem o real como uma práxis sem fim, isto é, ele compreende a relação contínua entre os polos ou linhas como uma atividade de luta e criação desprovida de qualquer termo ou meta, pois nela tudo está sempre por recomeçar e onde o devir corresponde à única finalidade desta práxis.
} 
de variação contínua ou de mudança a partir da qual ela se exerceria efetuando cortes imóveis ${ }^{2}$ ou segmentos bem determinados, isto é, tornando identificável aquilo que muda, tanto subjetivamente quanto objetivamente. $\mathrm{O}$ que está em jogo neste processo de endurecimento do fluxo contínuo da mudança é uma espécie de tentativa de controle da identidade e de subordinação disto que circula entre os segmentos ou escapa aos códigos da ação utilitária. Diretamente ligada ao conjunto dos interesses práticos e da sobrevivência da sociedade, a linha molar se efetua no campo social por meio das convenções e dos deveres impostos e coincide com a produção de uma linguagem coletiva e classificadora.

Sobre a linha molar, os aspectos da realidade se tornam claros e bem definidos, isto é, apresentam-se plenamente desenvolvidos. É a partir dela, neste sentido, que nós podemos criar planos e projetos, assim como elaborar previsões e antecipações, e nos localizarmos espaço-temporalmente através das referências fixas concebidas por seus segmentos. Por meio destes, elaboram-se os grandes conjuntos, do tipo Estado, instituições e classes sociais, através dos quais se impõem às nossas maneiras de pensar, sentir e perceber sistemas de alternativas ou de partilhas instituídas. Com isso, Deleuze e Guattari (1980) vão afirmar que as linhas de segmentos duros dependem de máquinas binárias que operam a partir de um princípio de dicotomia ou de oposição que age repartindo a vida através de um conjunto de distinções do tipo: jovem/velho, normal/patológico, individual/social, rico/pobre, trabalho/lazer, natureza/cultura etc., enfim, toda uma repartição rígida que organiza e cadencia nossas existências. Segundo este tipo de oposição que se expressa nas linhas molares, Deleuze e Parnet (1996) afirmam que existem "máquinas binárias de classes sociais, de sexos, homem-mulher, de idades, criança-adulto, de raças, branconegro, de setores, público-privado, de subjetivações, em nossa casa-fora de nossa casa" (p. 155). Os polos dicotômicos que se constituem nas linhas de segmentos duros formam oposições dialéticas que não criam qualquer tipo de abertura ou espaço livre, mas somente novos segmentos que nos situam em classes predeterminadas e nos limitam a fazer escolhas através de conjuntos binarizados.

A partir disto, portanto, as linhas molares se manifestam como políticas, de modo que devemos compreender com Deleuze e Parnet (1996) que os segmentos duros "implicam

\footnotetext{
${ }^{2}$ Sobre esta operação cf. DELEUZE, Gilles. Cinéma 1 - L'image-mouvement. Paris: Les Éditions de Minuit, 1983.
} 
também dispositivos de poder, bem diversos entre si, cada um fixando o código e o território do segmento correspondente" (p. 156). No entanto, é preciso compreender que "os poderes são segmentários e heterogêneos, e nada têm a ver com as abstrações vazias do Estado e 'da' Lei” (IDEM). As análises sociais elaboradas sobre este plano revelam apenas os aspectos organizados e instituídos no campo social, isto é, os padrões consolidados sob a forma de convenções, costumes e tradições que ocupam lugares bem definidos e facilmente identificáveis nas sociedades.

No entanto, de acordo com Deleuze e Guattari (1980), ao invés de isolar e fazer bastar a si própria a linha dura, é preciso considerar a criação, a conservação e a transformação desta linha, como decorrentes de sua relação com um outro tipo de linha, a linha de fuga ou de ruptura. É sobre esta que a linha dura opera os cortes e erige seus segmentos bem definidos, os quais, por sua vez, não param de ser atravessados pelos movimentos de fuga que os fazem romper.

Esta linha se caracteriza por uma mudança de coordenada ou de plano de referência e faz explodir as linhas segmentárias ao liberar um potencial de criação que as desestabilizam. No entanto, não se trata de fazer confundir ou transformar os sistemas de valor ou de códigos sobre os quais ela age, pois sua forma de desestabilização ou de desterritorialização é absoluta, e não relativa. Disto resulta, de acordo com Bouaniche (2007), “o caráter ativo das linhas de fuga, cujo próprio é ser atualizadas independentemente de toda prefiguração ou de todo determinismo causal” (p. 183). É preciso compreender ainda que estes movimentos disruptivos, que podem se produzir em um indivíduo, em uma sociedade ou em uma vida, também fazem parte do agenciamento coletivo e se operam através de uma máquina abstrata de mutação ${ }^{3}$. Assim, todo agenciamento possui pontas de desterritorialização por meio das quais ele mesmo foge, isto é, linhas de fuga através das quais ele "se estende ou penetra em um campo de imanência ilimitado que faz fundir os segmentos, ou ao menos luta ativamente contra eles e para dissolvê-los” (DELEUZE \& GUATTARI, 1975, p.154; grifos dos autores).

Dessa forma, fazer fugir um sistema, ou um mundo, ou uma sociedade, ou um agenciamento etc., significa abri-lo, ou melhor, impedi-lo de fechar-se sobre si mesmo.

\footnotetext{
${ }^{3}$ As máquinas abstratas de mutação se definem pelas pontas de descodificação e de desterritorialização que "abrem o agenciamento territorial para outra coisa, para agenciamentos de um outro tipo, para o molecular, o cósmico, e constituem devires” (DELEUZE \& GUATTARI, 1980, p. 637).
} 
No entanto, devemos compreender com Deleuze e Guattari (1980) que as linhas de fuga "não consistem nunca em fugir do mundo, mas antes em fazê-lo fugir, como se estoura um cano, e não há sistema social que não fuja/escape por todas as extremidades, mesmo se seus segmentos não param de se endurecer para vedar as linhas de fuga" (p. 249). Assim, do ponto de vista micropolítico, uma sociedade se define por suas linhas de fuga moleculares, ao invés de se definirem por suas contradições molares (o que só seria verdade do ponto de vista macropolítico). Desse modo, Deleuze e Parnet (1996) nos dizem que "em uma sociedade, tudo foge, e que uma sociedade se define por suas linhas de fuga que afetam as massas de toda natureza ("massa' é uma noção molecular)" (p. 164). Ou seja, é preciso compreender que apesar das linhas duras serem mais manifestas, elas não são suficientes para definir o campo social, pois esta compreensão da sociedade a partir das instituições e de seus costumes e tradições só pode ser considerada válida numa análise em grande escala.

Segundo Deleuze e Guattari (1980), estes fluxos ou estas linhas de fuga não param de correr entre os segmentos que se constituem a partir delas, escapando continuamente de sua totalização ou furtando-se da centralização que tentam subordiná-las. Neste sentido, as linhas de fuga se apresentam como os profundos movimentos que agitam a sociedade, já que "sempre vaza ou foge alguma coisa que escapa às organizações binárias, ao aparelho de ressonância, à máquina de sobrecodificação" (IDEM, p. 264). Assim, as linhas ou os movimentos de fuga devem ser considerados como primeiros em relação aos aspectos organizados do campo social, mesmo se eles não param de ser recobertos por todos os tipos de dispositivos que os regularizam, os domam, e os sufocam. Dessa forma, é preciso compreender que estes movimentos, "longe de ser uma fuga fora do social, longe de ser utópicos ou até mesmo ideológicos, são constitutivos do campo social, cujo declive e fronteiras, todo o devir, eles traçam" (DELEUZE \& PARNET, 1996, p. 163).

Dessa forma, é sempre a partir das linhas de fuga que se cria, é por elas que algo se compõe e que um plano de consistência é traçado. Por outro lado, as linhas duras, tomadas isoladamente, representariam um imobilismo conservador daquilo que se encontra constituído num indivíduo ou numa sociedade. Mas como algo se institui ou se constitui? Para responder a esta simples questão é preciso reivindicar a presença destes movimentos criadores que se expressam pelas linhas de fuga ou de ruptura dos segmentos dados, mas sempre em relação com as linhas duras. Neste sentido, devemos compreender 
que as desterritorializações efetuadas pelas linhas de ruptura sobre os segmentos bem definidos são recobertas ao mesmo tempo por movimentos de reterritorialização que insistem em colmatar as fugas.

É, por fim, a partir desta tensão ou desta imbricação entre estes dois conjuntos de linhas que surge um terceiro tipo de linha, ou melhor, um conjunto intermediário de linhas através do qual se operam devires ou movimentos de desterritorialização relativos. Tratase, portanto, da emergência da linha de segmentaridade flexível ou linha de fissura, que abordaremos na sequencia.

Esta linha deriva da relação entre as linhas dura e de ruptura. Considerada também como segmentada, a linha de fissura produz uma molecularização dos grandes segmentos, traçando pequenas modificações, infiltrações e micro-injeções nas instâncias molares. Não coincidindo com os grandes cortes segmentários, esta linha é também nomeada por Deleuze e Guattari (1980) de molecular ou de segmentaridade flexível. A flexibilidade e molecularidade desta linha decorrem da tensão que a linha de fuga exerce sobre a linha segmentária dura, ou seja, é a expressão dos processos de transformação que se produzem nos segmentos molares. Neste sentido, de acordo com Deleuze e Parnet (1996), "as linhas moleculares fazem passar, entre os segmentos, fluxos de desterritorialização que já não pertencem nem a um nem a outro, mas constituem o devir assimétrico de ambos” (p. 158). Isto é, trata-se de uma linha que se traça no meio dos segmentos, sobre a linha segmentária dura, arrastando-os num movimento de fuga que atrapalha sua binaridade e os faz entrar em movimentos de transformação.

O que se expressa através destas pequenas modificações, ou melhor, da introdução de um sistema de variação molecular no cerne das linhas de segmentos duros, é uma tendência a desfazer os códigos ou desmanchar os territórios e as normas que constituem o conjunto dos grandes segmentos sociais. No entanto, os processos de desterritorialização destas segmentaridades maleáveis são sempre relativos, de modo que os devires que ela aciona terminam por produzir uma organização diferente dos fenômenos, resultando na constituição de códigos polívocos e de território itinerantes (DELEUZE \& GUATTARI, 1980). Isto é, ela introduz uma abertura nos códigos e territórios, mas no sentido de torná-los múltiplos e capazes de captar as diferenças que chegam pelos acontecimentos. Esta flexibilidade produzida nos segmentos é o que nos permite escapar ao 
reconhecimento dos aspectos instituídos da dimensão molar da realidade social, ou seja, ao sistema de significações e valores definidos pelos códigos de nossa sociedade.

Tal operação da linha flexível consiste, portanto, num procedimento que ultrapassa os limiares ordinários da percepção, nos pondo em contato ou nos permitindo apreender alguma coisa de imperceptível que escorre sob os segmentos naturalizados, isto é, nos abre a toda uma vida molecular intensa que se desenrola sob os segmentos da existência e que constitui nosso devir. Assim, sob esta perspectiva, passamos a explorar os pequenos movimentos que escapam à nossa percepção ordinária, de modo que os elementos de nossa experiência deixam de ser claramente identificáveis em função dos grandes cortes e dos papéis designáveis pelas instâncias majoritárias da sociedade. É, portanto, nestas pequenas variações moleculares, e não nos cortes maiores de nossa história e pelo papel fixo que nos é imposto, que se dão as verdadeiras mutações, nos indivíduos e no campo social. Trata-se, desse modo, de desfazer as formas estáveis e identificáveis que decorrem dos dispositivos de poder e de assujeitamento, para encontrarmos o trabalho das multiplicidades moleculares que nos permitem produzir variações em nossos modos de perceber, sentir, pensar e agir.

Enquanto as linhas molares ou de segmentos duros agem formando territórios ou reterritorializando os fluxos moleculares a partir dos processos de sobrecodificação que constituem um plano de organização, as linhas moleculares ou de segmentos flexíveis procedem por desterritorializações relativas, constituindo mutações e conjugando fluxos a partir de um plano de consistência ou de imanência que arranca partículas das formas segmentárias e afetos dos sujeitos constituídos. No entanto, é preciso compreender que estas mutações são secretas, ou melhor, se fazem silenciosamente no limiar das formas ou grandes conjuntos. É como algo que se passa, no interior e no exterior dos segmentos, fazendo com que eles rachem ou "se quebrem exatamente como um prato ou um copo" (DELEUZE, 1969, p. 180). Trata-se, portanto, de uma abertura que se instala entre o interior e o exterior, ou melhor, uma fissura silenciosa que se acha na fronteira ou se estende numa superfície incorporal dos corpos ou segmentos bem definidos que ela abre, mantendo relações de interferência com aquilo que lhes acontece.

Situada entre a linha de fuga, com suas desterritorializações absolutas, e a linha segmentada dura que opera os bloqueios ou as reterritorializações disto que vaza, a 
segmentaridade maleável emerge na fronteira como uma espécie de zona de mediação ou superfície de tensão. Neste ponto de equilíbrio metaestável, a linha de fissura tende a tombar para um lado ou para o outro, isto é, ela resiste ao endurecimento da linha de corte, ao mesmo tempo em que teme se precipitar passivamente na desterritorialização absoluta da linha de ruptura - "essa é a sua ambiguidade" (DELEUZE \& GUATTARI, 1980, p. 250). É por ela que devimos, que criamos deslocamentos relativos em nossas maneiras habituais de sentir e perceber o mundo, mas é por ela também que somos convocados a criarmos ativamente modos inéditos de vida, quando sua passagem nos desestabiliza a tal ponto que não nos resta outra coisa senão traçar ativamente a própria criação de uma nova maneira de nos relacionar com o que nos acontece.

Estas três linhas são imanentes e não param de se remeter umas às outras, elas se cruzam constantemente, se superpõem e se seguem por um instante. O que se constituem a partir destas relações imanentes das linhas são mapas, isto é, elas traçam um percurso intensivo daquilo que é segmentado em nós, daquilo que se move e possibilita pequenas variações e, enfim, daquilo que nos atravessa e faz romper nossas segmentaridades. O mapa expressa, portanto, o traçado de uma experimentação ancorada nos movimentos reais que nos atravessam e pelos quais nos constituímos e nos modificamos. Assim, é preciso apreender as linhas e os movimentos que nos constituem e nos atravessam, que nos fecham a determinadas segmentaridades ou nos abrem a novas conexões, a cada vez e em cada modo de vida, em grupos ou indivíduos.

No que diz respeito à apreensão das linhas que compõem nossos mapas, é preciso compreender que elas não possuem algum sentido oculto e nada querem dizer, isto é, elas não devem ser tomadas como objeto de interpretação. O estudo dessas linhas e seus movimentos, em indivíduos e grupos sociais, é antes objeto de uma tarefa cartográfica. Seu procedimento de análise consiste em traçar mapas, e desse modo se contrapõe ao modelo estrutural ou gerativo que procede por decalques e fotografias, cuja finalidade é fazer uma descrição de algo já constituído a fim de submeter a uma lógica da reprodução. Neste modelo, os dados da realidade são apreendidos sob a forma de unidades acabadas e identificáveis, de acordo com um princípio de semelhança, que anulam as pequenas variações e põem em relevo apenas os grandes conjuntos. Ao contrário do decalque, cuja operação se limita a reproduzir um sistema de representações que se fecha sobre si próprio e que volta sempre "ao mesmo", o mapa forma um sistema aberto e de múltiplas entradas, 
ele "é conectável em todas as suas dimensões, desmontável, reversível, suscetível de receber modificações constantemente" (DELEUZE \& GUATTARI, 1980, p. 20).

\section{Riscos e perigos das linhas}

No entanto, não cabe unicamente considerar satisfatória a perspectiva de Deleuze e Guattari que compreende o real como linhas ou multiplicidades que agem ludicamente umas sobre as outras, como se suas relações fossem voluntárias e isentas de conflitos e riscos. Neste sentido, nos resta enumerar os perigos que cada linha comporta e compreender o aspecto imanente a partir do qual elas se enredam entre si e trabalham umas nas outras. Segundo Deleuze e Guattari, as análises dessas linhas estão isentas de qualquer avaliação moral, de maneira que,

\footnotetext{
não podemos dizer destas três linhas que uma seja má e outra boa, por natureza e necessariamente. $\mathrm{O}$ estudo dos perigos sobre cada linha é o objeto da pragmática ou da Esquizoanálise, visto que ela não se propõe a representar, interpretar nem simbolizar, mas somente a fazer mapas e traçar linhas, marcando suas misturas tanto quanto suas distinções (1980, p. 227).
}

Inicialmente, o perigo que concerne exclusivamente à linha dura é o Medo. Diante de seu endurecimento de difícil modificação e marcado por uma rigidez que nos assegura conforto e proteção, temos medo de perder a segurança da grande organização molar que nos sustenta. Assim, fugimos diante da fuga, isto é, frente à possibilidade de desestabilização ou dissolução dos nossos segmentos. Tornamo-nos "as criaturas mais medrosas, as mais impiedosas também, as mais amargas" (DELEUZE \& PARNET, 1996, p. 166), endurecendo ainda mais nossos segmentos e nos entregando à lógica binária. Fugimos diante da crise que embaralha os nossos códigos e atrapalha o conforto territorial de nossas ligações habituais com o mundo, pois "quanto mais a segmentaridade for dura, mais ela nos tranquiliza" (DELEUZE \& GUATTARI, 1980, p. 278). Eis, portanto, por que somos impelidos para a linha dura, eis o que é nosso medo.

Há ainda outro perigo que concerne às linhas duras, o Poder. Este perigo, segundo Deleuze e Parnet (1996), aparece em toda parte através de todos “os dispositivos de poder que trabalham nossos corpos, todas as máquinas binárias que nos recortam, as máquinas abstratas que nos sobrecodificam" (p. 166), agindo sobre nossa maneira de perceber, de agir e de sentir. Neste sentido, a operação que caracteriza o poder consiste em deter as linhas de fuga e fixar a máquina de mutação, produzindo nos agenciamentos em questão 
as condições de seu próprio fechamento. Mas este perigo se encontra também nas linhas moleculares, já que a segmentaridade flexível corre o risco de reproduzir em miniatura as afecções da linha dura, de modo que "podemos encontrar sobre uma linha flexível os mesmos perigos que sobre a dura, simplesmente miniaturizados, disseminados ou, antes, molecularizados" (DELEUZE \& PARNET, 1996, p. 167), e estabelecer micro-édipos ou microfascismos.

A linha flexível ou de fissura comporta, por sua vez, um tipo de perigo que corresponde ao modo de percepção que ela possibilita: a Clareza. Neste sentido, para Deleuze e Guattari, a clareza concerne ao molecular, a uma percepção molecular que revela espaços e vazios, como buracos na estrutura molar (distinções que se estabelecem naquilo que nos parecia pleno), onde tudo se torna flexibilidade aparente e adquire a clareza do microscópio. Além do mais, as próprias linhas de fissura produzem ou afrontam seus próprios perigos na medida em que transpõem depressa demais um limiar, produzindo a permanência da abertura a intensidades perigosas por mais tempo do que se poderia suportar e assim fazer o processo molecular cair num buraco negro, isto é, habitar um mundo perceptivo molecular. Mas este é apenas um dos lados para o qual sua ambiguidade pode tender e se perder na linha de ruptura. No sentido contrário, ela adota o risco das linhas duras ao despertar um medo profundo de dissolução e tender a reterritorializações que nos fecham em segmentos mais endurecidos.

Embora a linha de fuga seja frequentemente apresentada como uma espécie de linha de mutação ou de criação que se traça no tecido da realidade e do campo social, e apesar de sua mensagem de alegria que nos traz a passagem de um ar renovado, o perigo que ela porta não se reduz apenas ao risco de ser barrada, reduzida, colmatada, segmentarizada, reterritorializada pela linha dura, ou precipitada num buraco negro pela linha molecular. Mas ela tem um risco particular a mais, que talvez seja o pior: ela comporta um estranho desespero, "como se algo a ameaçasse exatamente no âmago do seu próprio empreendimento, uma morte, uma demolição, no exato instante onde tudo se esclarece" (DELEUZE \& GUATTARI, 1980, p. 251). Ela produz um estado de desespero tal como um estado de guerra do qual se sai destroçado, desfeito, depois de haver destruído tudo o que se podia. Neste sentido, de acordo com Deleuze e Guattari (1980), o perigo é "que a linha de fuga atravesse o muro, que ela saia dos buracos negros, mas que, ao invés de se conectar com outras linhas e aumentar suas valências a cada vez, ela se transforme em 
destruição, abolição pura e simples, paixão de abolição" (p. 280; grifo dos autores). É sobre esta linha destrutiva que o fascismo e o terrorismo se constituem, precipitando todas as linhas numa queda suicida que desfaz violentamente todos os segmentos.

Este é, portanto, o perigo especial desse tipo de linha e que se mistura, mas não se confunde, com os perigos das linhas duras e flexíveis: converter-se em linha de abolição, inverter seu processo de criação e tornar-se linha de destruição, das outras linhas e de si mesma. Neste sentido, as análises da linha de fuga e dos seus riscos nos aproximam da questão central da criação ou da produção da novidade e dos devires que aqui perseguimos.

\section{Experimentação e prudência: avaliação dos riscos e dos fatores de criação}

Trata-se, todavia, de compreender que o obstáculo à novidade não corresponde apenas a fatores de anti-criação exteriores ao seu processo de aparição (códigos, normas, conformismo, censura etc.), mas que ele surge também e sobretudo do interior do processo de criação que pode recair ou degenerar e se orientar para a destruição. Dessa forma, ora a novidade é considerada em relação a um limite relativo e extrínseco que ela encontra e que, sem destruí-la, fixa ou bloqueia seu processo, buscando sufocá-la, canalizá-la para captá-la em seu proveito. Ora, sobre outro plano, ela é exposta ou confrontada com o seu limite oposto, absoluto e intrínseco, a destruição ou a abolição.

Tanto num caso quanto no outro a tarefa consiste em abrir os problemas práticos a fim de liberar as linhas, sejam as de uma vida, as de um indivíduo ou as de uma sociedade, mas para isso é necessário convocar experimentações nas quais é preciso proceder com paciência e prudência. Neste sentido, esta prática deve ser compreendida necessariamente como uma ética que põe a criação na existência, pois nela tudo é caso de limiares ou de determinação a cada vez singular entre aquilo que convém e aquilo que não convém, entre o que compõe relações vantajosas, no sentido de um crescimento da potência da criação, e aquilo que as decompõem. É possível, neste sentido, que haja diversas combinações das linhas, mas também problemas de composição entre elas, de uma linha com a outra, pois não é certo, por exemplo, que duas linhas de fuga sejam compatíveis ou compossíveis, pois "a linha de fuga de alguém, grupo ou indivíduo, pode muito bem não favorecer a de outro; pode, ao contrário, barrá-la, interditá-la a ele, e lançálo ainda mais em uma segmentaridade dura" (DELEUZE \& GUATTARI, 1980, p. 250). 
Assim, é preciso que se faça, através de uma análise das linhas em relação, uma avaliação dinâmica que leve em consideração o devir dos agenciamentos, conduzindo dessa forma a uma análise dinâmica do real. Porém, não basta apenas classificar os diferentes tipos de linha para tentar dominar a multiplicidade, mas é preciso ainda triar, desembaraçar e selecionar as diferentes linhas em função de sua capacidade criadora.

Esta avaliação, por sua vez, deve ser considerada a partir de novos critérios, que não são mais aqueles que analisam o campo social através de seus aspectos identitários, históricos, formais e estruturais, mas que procura avaliá-lo em função de seus potenciais de mutação. Neste sentido, de acordo com Deleuze e Parnet, "o que seria preciso comparar em cada caso são os movimentos de desterritorialização e os processos de reterritorialização que aparecem em um agenciamento" (1996, p. 161), ou seja, os coeficientes variáveis em cada situação. Isto é, trata-se de buscar dar conta dos movimentos de transformação capazes de se produzirem em um indivíduo, em uma vida e em uma sociedade, sem esquecer também de estar atento aos perigos que cada uma das linhas que os compõem porta em si mesma.

Para alcançarmos suas zonas de potência a partir das linhas duras, é preciso manejá-las a ponto de amolecê-las, flexibilizá-las, suspendê-las de vez em quando e miná-las do interior, isto é, torna-se necessário desfazer seus segmentos até um certo ponto a fim de evitar sua destruição total de uma só vez, pois é indispensável preservar um mínimo de segmentaridade para sobreviver. Esta experimentação, por sua vez, exige que se tenha precaução e paciência ao desfazer o segmento duro, de modo que "é preciso diminuí-lo, estreitá-lo, limpá-lo, e isto ainda em alguns momentos" (DELEUZE \& GUATTARI, 1980, p. 201). Trata-se, portanto, de abri-lo a novas conexões que supõem toda uma multiplicidade de "agenciamentos, circuitos, conjunções, superposições e limiares, passagens e distribuições de intensidade, território e desterritorializações" (IDEM, p. 198), tudo isto através de um longo trabalho que não se faz apenas contra os Estados e os poderes que insistem em colmatar e sufocar as linhas de fuga que os dissolve, mas diretamente sobre si.

Por outro lado, no que diz respeito às linhas de fuga, é preciso todo um esforço de criação e toda uma arte para traçá-las, e ainda evitar o contrassenso a partir do qual a linha de fuga deve ser buscada a qualquer custo, já que seu traçado pode se desviar ao ponto de 
revertê-la em linha de abolição. Assim, o traçado da linha de fuga deve se fazer de acordo com um critério outro do que a fuga por ela mesma. Neste sentido, é preciso avaliar a linha de fuga em função de sua capacidade de crescer e se conectar com outras linhas, e a aumentar suas valências a cada vez, isto é, a partir de sua capacidade transformadora, e não em função de sua capacidade em entrar nos agenciamentos terroristas e fascistas que a transformariam em destruição, linha de morte, abolição pura e simples. No entanto, devemos compreender com Deleuze e Parnet que "é sempre sobre uma linha de fuga que se cria, porque se traça algo real e compõe-se um plano de consistência" (1996, p. 164). Porém, é preciso compreender que as reterritorializações se fazem ao mesmo tempo.

Com isso, devemos considerar que a análise de cada uma das linhas não pode prescindir de sua relação contínua com as demais, de sua determinação recíproca e coexistência através da qual elas se misturam e se transformam. Também é preciso compreender que estas linhas não preexistem às suas determinações atuais, mas se traçam e se compõem ao mesmo tempo, imanentes umas às outras, emaranhadas umas nas outras, de modo que nunca se sabe de antemão o que vai funcionar como linha de declive e nem a forma do que virá barrá-la.

Das três linhas coexistentes, podemos considerar que a linha molar e a linha de ruptura formam os polos de um circuito através do qual se determinam os processos de criação e seus fracassos, e que a linha molecular apareceria apenas como oscilando entre os dois extremos, ora levada pela conjugação dos fluxos de desterritorialização, ora relacionada com a acumulação das reterritorializações. No entanto, devemos compreender com Deleuze e Parnet (1996) que não se trata de “um dualismo entre duas espécies de 'coisas', mas de uma multiplicidade de dimensões, de linhas e de direções no seio de um agenciamento" (p. 160). Apesar da diferença de natureza entre elas, "acontece mesmo que as duas linhas se alimentam uma da outra, e que a organização de uma segmentaridade cada vez mais dura entre em circuito com a gestão dos pequenos terrores e dos buracos negros em que cada um mergulha na rede molecular" (IDEM, p.168). Neste sentido, as linhas formam planos que se distinguem, mas não se separam, se relacionam continuamente e garantem nossas variações dinâmicas em diversos níveis.

Por fim, interessa para Deleuze e Guattari cartografar aquilo que impede e bloqueia os processos de mutação, e aquilo que os favorece, levando em consideração os riscos e 
perigos que os lineamentos portam. Isto significa apreender estas linhas em seu processo de remissão contínuo, compreendendo que o jogo das resistências se configura como um combate perpétuo na imanência no qual devemos intervir nos contextos em que estamos inseridos e nos agenciamentos em que estamos engajados a fim de favorecer os devires e mutações que atravessam os modos de vida individuais e os campos sociais.

\section{REFERÊNCIAS}

AGAMBEN, Giorgio. A imanência absoluta. In: ALLIEZ, Éric. Gilles Deleuze: uma vida filosófica - São Paulo: Ed. 34, 2000.

BOUANICHE, Arnaud. Gilles Deleuze, une introduction. Paris: Pocket, 2007.

DELEUZE, Gilles. Logique du sens. Paris: Les Éditions de Minuit, 1969.

Cinéma 1 - L'image-mouvement. Paris: Les Éditions de Minuit, 1983.

DELEUZE, G. \& GUATTARI, F. Kafka - Pour une littérature mineure. Paris: Les Éditions de Minuit, 1975.

. Capitalisme et schizophrénie 2. Mille Plateaux. Paris: Les Éditions de Minuit, 1980.

DELEUZE, G. \& PARNET, C. Dialogues. Paris: Flammarion, 1996.

MENGUE, Philippe. Gilles Deleuze ou le système du multiple. Paris: Édition Kimé, 1994.

\section{NOTAS DE AUTORIA}

Danilo Melo (danilomelo.uff@gmail.com) é graduado em Psicologia pela UFS, mestre em Psicologia pela UFF e doutor pelo Programa de Pós-graduação em Memória Social da UNIRIO. Realizou pesquisa de Pós-doutorado no Programa de Pós-graduação em Educação da UERJ com bolsa do CNPq. É professor adjunto do curso de Psicologia da UFF (Campus Universitário de Rio das Ostras). É líder do Grupo de Pesquisa "Individuação, Subjetividade e Criação", registrado no diretório do CNPq. Tem experiência nas áreas: Processos Psicológicos Básicos, Filosofia da Educação e Memória Social, 
atuando principalmente nos seguintes temas: Memória, Percepção, Produção de Subjetividade e Criação, Experiência do Pensamento e Ensino de Filosofia.

\section{Como citar este artigo de acordo com as normas da revista?}

MELO, Danilo. Experimentação e prudência no pensamento rizomático de Deleuze e Guattari. Texto Digital, Florianópolis, v. 16, n. 1, p. 3-19, 2020.

\section{Contribuição de autoria}

Não se aplica.

\section{Financiamento}

Não se aplica.

Consentimento de uso de imagem

Não se aplica.

\section{Aprovação de comitê de ética em pesquisa}

Não se aplica.

\section{Licença de uso}

Este artigo está licenciado sob a Licença Creative Commons CC-BY. Com essa licença você pode compartilhar, adaptar, criar para qualquer fim, desde que atribua a autoria da obra.

\section{Histórico}

Recebido em: 13/05/2020.

Aprovado em: 15/05/2020. 